\title{
PREVALENCE OF DENTAL DECAY AND PERIODONTAL DISEASES AMONG CHILDREN SUFFERING FROM CONGENITAL HEART DISEASES. A LITERATURE REVIEW - PART III
}

\author{
Teodora Nikolova ${ }^{1}$, Radosveta Andreeva ${ }^{1}$, Milena Georgieva ${ }^{1}$, Petar Shivachev ${ }^{2}$ \\ ${ }^{1}$ Department of Pediatric Dental Medicine, Faculty of Dental Medicine, \\ Medical University of Varna \\ ${ }^{2}$ Department of Pediatric Medicine, Faculty of Medicine, Medical University of Varna
}

\begin{abstract}
Congenital heart diseases (CHDs) are known to be related to structural and developmental disturbances of teeth, such as anodontia, microdontia, enamel hypoplasia, affected normal form of teeth. A recent research points out that enamel and dentin of primary teeth of children with CHD are structurally and chemically altered, with low calcium and phosphorus levels.

Tooth decay and periodontal diseases have low morbidity rates, but they both have high prevalence and cause oral pain. They are risk factors for other systemic complications, most likely in children. Children with CHD are at higher risk of complications, because their main disease may worsen due to oral diseases. The main risk is life-threatening systemic conditions such as infectious endocarditis and brain abscess, caused by odontogenic bacteremia.
\end{abstract}

The available information, concerning oral manifestations and specifics in the dental clinics and prophylaxis of children with CHD, is still scarce and insufficient despite the social significance of this problem.

Keywords: congenital heart disease (CHD), dental decay, periodontal disease, children, risk factors, medication

Address for correspondence:

Teodora Nikolova

Faculty of Dental Medicine

84, Tsar Osvoboditel Blvd.

9000 Varna

e-mail:tedinikolova1@gmail.com

Received: June 3, 2018

Accepted: June 29, 2018
Retarded eruption of teeth, orthodontic anomalies, enamel hypoplasias and poor oral hygiene due to distraction, caused by the cardiac disease, are common clinical findings among patients with congenital heart disease (CHD) (1). A recent study finds that enamel and dentin of primary teeth of children with CHD have lower amounts of calcium and phosphate in their compound than the average expected in healthy children $(2,3)$.

CHDs are known to be linked to structural and developmental disturbances of teeth such as anodontia, microdontia, enamel hypoplasia, dental dysmorphia (3-9). There is a proof for cross-linked inheri- 
Prevalence of Dental Decay and Periodontal Diseases Among Children Suffering from Congenital Heart Diseases. ...

tance of bicuspid aortic valve (BAV) and some developmental disturbances of teeth, such as anodontia and microdontia $(3,6,10,11)$.

Patients with CHD are at risk of enamel hypoplasia of primary teeth and at even higher risk of early childhood caries (ECC), due to sugar, added to pharmaceutical preparations. This implies the need for active prevention, such as placing sealants on primary molars right after eruption, regular exogenous fluoride applications, proper diet and control of feeding habits, chewing of gums without sugar and some other means for maintaining adequate personal oral hygiene (3).

Patients with CHD are at high risk of dental decay and periodontal diseases development, as well as for systemic complications due to oral health problems $(5,6,12)$. Such patients still show unsatisfactory levels of oral health, though $(14,15)$.

According to a recent clinical study with a response rate of $67 \%$, caries prevalence in children with CHD at $1-5 \mathrm{dmft}$ was $37.3 \%$ and at 3-5 dmft it was $25.4 \%$ (13). Few children $(n=4)$ had untreated decays, indicating an unmet need for operative treatment. Enamel lesions (d1-2s) exceeded dentine lesions (d35 s) in the study group, $60 \%$ versus $40 \%$, indicating a significant need of non-operative treatment. At dentine level, caries prevalence in children with CHD was significantly higher than in children in the general population (25.4 versus 18.3\%). Erosion was more prevalent than caries (50.7 versus $37.3 \%$ ) (13). In total, $37.3 \%$ of all children had d $3-5 \mathrm{mfs}$ caries, erosion (grades 3 or 4), developmental defects of enamel (DDE) with post-eruptive breakdown of enamel and exposure into dentine, or combinations of the diagnoses. Investigated background factors did not significantly affect caries, erosion, or DDE (13).

Some studies on the dental knowledge and attitudes of children with a CHD and their caregivers have yielded unsatisfactory results with regard to oral hygiene practices and the use of dental services (7, 16-19). A study conducted in Brazil in 2002 found that $28.8 \%$ of children with a CHD had never visited a dentist $(16,20)$. The authors also reported that $47.1 \%$ of these children brushed their teeth more than once daily, which was below expectations despite the fact that brushing was performed with parental supervision (16,20). A study undertaken in the UK in 1996 showed that caregivers of children with a CHD attended fewer regular dental check-ups for their children than caregivers of children with no medical problems $(16,21)$.

In studies from several developing countries, caregivers of children with a CHD reported being less aware about the link between CHDs and oral diseases and the increased risk of their children developing infective endocarditis $(16,20,22,23)$. However, in studies from other developed countries, caregivers had fairly better knowledge $(12,16,24)$.

In another recent study in Sudan, a significantly higher prevalence of caries and gingivitis among children aged 3-12 years with a CHD than among those without a CHD, was found (16). The role of the caregiver of a child with a CHD, in terms of practicing daily oral health activities and possessing oral health knowledge, has been recognized to be a risk factor of great importance $(1,16,25)$.

An unexpected finding in the same research was the effect that use of fluoridated toothpaste had on the prevalence of caries among CHD cases (16). Children with a CHD who frequently used fluoridated toothpaste had a significantly higher likelihood of caries than infrequent users. One explanation may be that the amount of fluoride in the toothpaste and frequency of brushing were insufficient to confer full protection (16). Also, the CHD cases represent a group in need of extra means of fluoride application. Another possible explanation may be that the contribution of other background factors to the deterioration of the oral health of children with a CHD might have reduced the effectiveness of fluoride against dental caries (16).

Oral Manifestations Concerning Marginal Periodontium

Depressed salivary flow and gingival inflammation are common oral problems for children with $\mathrm{CHD}$, due to long-term pharmacotherapy. Some medications are proven to lower overall salivary secretion and thus saliva cannot properly protect oral mucosa, which may result in gingivitis (16).

Gingival inflammation is a common clinical finding among children with CHD and this implies the need for some invasive clinical procedures. It is recommended that these planned clinical visits take place late in the morning, in calm and peaceful sur- 
Teodora Nikolova, Radosveta Andreeva, Milena Georgieva et al.

rounding (3). Effective local anesthesia is indicated. Anesthetics should not contain adrenaline since it raises blood pressure, causes heart arrhythmias and interferes with beta-blocker therapy. Dental medics should also be careful when using retraction cords with adrenaline (3).

A clinical study finds that children with CHD have significantly higher mean values of registered periodontal sites with plaque and gingivitis than healthy controls (Ctr.), though nearly all children had plaque registered. The patients with $\mathrm{CHD}$ presented significantly higher mean values of $\mathrm{dmft} / \mathrm{DMFT}$ indices than Ctr.- for age group 1 (including children aged 3-7), dmft/DMFT for CHD was 3.7 against 2.3 for the (Ctr.) and for age group 2 (8-12) - 1.3 for CHD against 0.6 for Ctr. The lack of registered fillings despite the high $\mathrm{dmft} / \mathrm{DMFT}$ indices is a concerning finding (26).

Again, given the use of different indices, caution is also required when comparing results for plaque and gingivitis among different reports. In the present study, gingivitis and plaque were found to be highly prevalent among children with CHDs, and the percentages were much higher than in previous studies (1). Fifteen of the cases in the present study were found to have gingival hyperplasia. This may be attributed to the use of CHD medications (anti-hypertensive drugs to reduce the pulmonary hypertension caused by some of the CHDs) (1).

The available information, concerning oral manifestations and specifics in the dental clinics and prophylaxis of children with CHD, is still scarce and insufficient despite the social significance of this problem $(5,6)$.

Risk of Systemic Complications Due to Oral Disease in Children with CHD

The proven risk of infectious endocarditis after invasive dental treatment of patients with CHD is due to the ability of Streptococcus mutans to adhere to endocardium. The transitional odontogenic bacteremia after dental procedures is said to last from 15 minutes to an hour. Dental manipulations, suspected of causing odontogenic bacteremia, include extractions of teeth, professional oral hygiene and some other periodontal therapy procedures, rubber dam placement, endodontic over-instrumentation beyond the apical foramen, even careless personal oral hy- giene procedures (3). The prophylaxis of odontogenic bacteremia includes rinsing with $2 \%$ chlorhexidine gluconate before dental procedures and possible antibiotic coverage for 14 days, started at least 6 hours before invasive manipulations. Common prescriptions for antibiotic prophylaxis include Amoxicillin, Ampicillin, Cephalexin - 50mg/kg, Clindamycin $(20 \mathrm{mg} / \mathrm{kg})$, Azithromycin $(15 \mathrm{mg} / \mathrm{kg})$. In some cases only a single antibiotic intake, at least 3 hours before dental procedure, is indicated (3). Antibiotic prophylaxis is indicated before all invasive procedures on gingiva, oral mucosa and periapical alveolar bone. There is no need of it before local infiltrative anesthesia of non-inflamed tissues, X-rays, adjusting of orthodontic or prosthodontic appliances or physiological exfoliation of primary teeth (3).

As a result of progress in medical procedures and the use of prosthetic materials for correction of CHDs, the prognosis for these patients has improved. Children with CHDs now have a greater life expectancy, and many of them reach adulthood (1, 27). Nevertheless, these children remain at a higher risk than healthy children of developing serious and potentially fatal heart-related infections, such as infective endocarditis $(1,27)$. Infective endocarditis of oral origin was thought to be associated only with invasive dental procedures, through the entry of oral bacteria into the systemic circulation (for example, Streptococcus viridans, S. sanguinus, and S. mutans) $(1,13)$. However, later studies have shown that it can be caused by everyday bacteremia, associated with routine daily activities such as chewing, flossing, and tooth brushing $(1,28)$. Moreover, children with CHDs are also susceptible to development of various oral diseases $(1,13)$.

When general condition is unstable, children with CHD should only receive palliative oral care. Vital pulpotomies and pulpectomies are contraindicated due to the possibility for chronic bacteremia. It is recommended for dental medics to avoid treatment plans that imply multiple visits and long-term antibiotic coverage (3). Treatment of many oral conditions, which involve invasive treatment, is indicated under full anesthesia and medical control. For children with $\mathrm{CHD}$, possible intake of anti-coagulant, anti-arrhythmic and/or anti-hypertensive medication should be considered. Children with pace- 
Prevalence of Dental Decay and Periodontal Diseases Among Children Suffering from Congenital Heart Diseases. ...

makers are contraindicated for electric pulp testing (EPT) and ultrasound instrumentation (3).

Generally, caries and periodontal diseases have low morbidity, but both have high prevalence and are responsible for dental pain and teeth loss. They are also risk factors for other systemic complications, especially among children $(3,16,29)$. Children with CHDs are at disadvantage because due to their underlying medical condition, the development of an oral disease can put their general health at risk $(3,16)$.

The main risks, caused by odontogenic bacteremia, are infectious endocarditis and brains abscesses - both life-threatening conditions $(3,16,30)$. Recent changes in the recommendations for prevention of infective endocarditis in children with CHDs have limited antibiotic prophylaxis to certain types of CHD and highlighted the importance of non-antibiotic prophylaxis $(16,31,32)$. It has been emphasized that finding ways to prevent oral health problems in children with a CHD is now more important than ever $(16,31,32)$.

\section{CONCLUSION}

Children with CHD have poor oral health. Common clinical findings are the high number of untreated decayed teeth, poor oral hygiene and associated gingivitis, in primary as well as in permanent dentitions.

These findings are bothering because of the potential risk of infective endocarditis for this group of children (1). For children with CHDs in particular, the healthy oral cavity is one direction in avoiding life-threatening complications. Epidemiological studies, focusing on the oral health of children with CHDs, are necessary to provide baseline data for planning future preventive strategies (1).

With the growing concern about the oral problems related to CHDs, several studies in different countries have compared the caries experience of children with CHDs to that of those without CHDs. In some of these studies, the prevalence of caries and gingivitis among children with CHDs was much higher than in their counterparts $(1,5,33)$. However, other studies failed to demonstrate such differences $(1,21,26)$. One study even reported better oral health parameters among children with CHDs than among other children $(1,23)$. These controversial results imply the need for further controlled clinical trials.

\section{REFERENCES}

1. Garrocho-Rangel A, Echavarría-García A, RosalesBérber M, Flores-Velázquez J, Pozos-Guillén A. Dental management of pediatric patients affected by pulmonary atresia with ventricular septal defect: A scoping review. Med Oral Patol Oral Cir Bucal. 2017; 22(4): e458-e466.

2. Ali HM, Mustafa M, Hasabalrasol S, Elshazali OH, Nasir EF, Ali RW, et al. Presence of plaque, gingivitis and caries in Sudanese children with congenital heart defects. Clin Oral Investig. 2017; 21(4): 12991307. doi: 10.1007/s00784-016-1884-2.

3. El-Hawary YM, El-Sayed B, Abd-Alhakem G, Ibrahim FM. Deciduous teeth structure changes in congenital heart disease: ultrastructure and microanalysis. Interv Med Appl Sci. 2014;6(3):111-117. doi: 10.1556/IMAS.6.2014.3.3.

4. Bird DL, Robinson DS. Evolve resources for modern dental assisting. 11th ed. Elsevier-Saunders; 2015. p. 258.

5. Hallett KB, Radford DJ, Seow WK. Oral health of children with congenital cardiac diseases: a controlled study. Pediatr Dent. 1992;14(4):224-30.

6. Raducanu AM, Feraru IV, Suicu I, Teodorescu E, Andidelescu AC, Ionescu I et al. Common and unusual dental development abnormalities in a patient with bicuspid aortic valve. Rom J Morphol Embryol. 2016;57(2 Suppl):871-3.

7. Satish C, Shaleen C, Girish C, Kamala R. Oral medicine. Jaypee Brothers Medical Publishers; 2007. p. 153-8.

8. Kouskoura T, Fragou N, Alexiou M, John N, Sommer L, Graf D, et al. The genetic basis of craniofacial and dental abnormalities. Schweiz Monatsschr Zahnmed. 2011;121(7-8):636-46.

9. Miletich I, Sharpe PT. Normal and abnormal dental development. Hum Mol Genet. 2003, 12(Spec No 1):R69-R73.

10. American Academy of Pediatric Dentistry (AAPD). Guideline on periodicity of examination, preventive dental services, anticipatory guidance/counseling, and oral treatment for infants, children, and adolescents. Pediatr Dent. 2013; 35(5): E148-E156.

11. D'Souza RN, Kapadia H, Vieira AR. Teeth. In: Stevenson RE, Hall JG (eds). Human malformations and related anomalies. 2nd edition, Oxford University Press, 2006, 425-468. 
Teodora Nikolova, Radosveta Andreeva, Milena Georgieva et al.

12. Chandna $P$, Adlakha VK. Infant oral health. In: Virdi MS (ed). Emerging trends in oral health sciences and dentistry. Rijeka, Croatia: InTech; 2015.p. 151-64.

13. Sivertsen TB, Asmus J, Greve G, Åstrøm AN, Skeie MS. Oral health among children with congenital heart defects in Western Norway. Eur Arch Paediatr Dent. 2016;17(5):397-406. doi: 10.1007/ s40368-016-0243-y.

14. Nederfors T, Twetman S, Dahlof C. Effects of the thiazide diuretic bendroflumethiazide on salivary flow rate and composition. Scand J Dent Res. 1989;97(6):520-7.

15. FitzGerald K, Fleming $P$, Franklin O. Dental health and management for children with congenital heart disease. Prim Dent Care. 2010;17(1):21-5. doi: 10.1308/135576110790307690.

16. Ali HM, Mustafa M, Nasir EF, Lie SA, Hasabalrasol S, Elshazali OH, et al. Oral-health-related background factors and dental service utilisation among Sudanese children with and without a congenital heart defects. BMC Oral Health. 2016;16(1):123.

17. Berger EN. Attitudes and preventive dental health behaviour in children with congenital cardiac disease. Aust Dent J. 1978;23(1):87-90.

18. Lowry LY, Evans DJ, Lowry RJ, Welbury RR. Under-registration for dental care of children with heart defects in the north-east of England: A comparative study. Prim Dent Care. 1996;3(2):68-70.

19. Suvarna R, Rai K, Hegde AM. Knowledge and oral health attitudes among parents of children with congenital heart disease. Int J Clin Pediatr Dent. 2011;4(1):25-8. doi: 10.5005/ jp-journals-10005-1076.

20. da Silva DB, Souza IP, Cunha MC. Knowledge, attitudes and status of oral health in children at risk for infective endocarditis. Int J Paediatr Dent. 2002; 12(2):124-31.

21. Franco E, Saunders CP, Roberts GJ, Suwanprasit A. Dental disease, caries related microflora and salivary IgA of children with severe congenital cardiac disease: an epidemiological and oral microbial survey. Pediatr Dent. 1996;18(3):228-35.

22. Pucéat M. Embryological origin of the endocardium and derived valve progenitor cells: from developmental biology to stem cell-based valve repair. Biochim Biophys Acta. 2013;1833(4): 917-22. doi: 10.1016/j.bbamcr.2012.09.013.
23. Suma G, Usha MD, Ambika G, Jairanganath. Oral health status of normal children and those affiliated with cardiac diseases. J Clin Pediatr Dent. 2011;35(3):315-8.

24. Grahn K, Wikstrom S, Nyman L, Rydberg A, Stecksen-Blicks C. Attitudes about dental care among parents whose children suffer from severe congenital heart disease: a case-control study. Int J Paediatr Dent. 2006;16(4):231-8. doi: 10.1111/j.1365-263X.2006.00736.x.

25. Christensen LB, Twetman S, Sundby A. Oral health in children and adolescents with different socio-cultural and socio-economic backgrounds. Acta Odontol Scand. 2010;68(1):34-42. doi: $10.3109 / 00016350903301712$.

26. Tasioula V, Balmer R, Parsons J. Dental health and treatment in a group of children with congenital heart disease. Pediatr Dent. 2008;30(4):323-8.

27. Ferrieri P, Gewitz MH, Gerber MA, Newburger JW, Dajani AS, Shulman ST, et al. Unique features of infective endocarditis in childhood. Circulation. 2002;105(17):2115-26.

28. Lockhart PB, Brennan MT, Sasser HC, Fox PC, Paster BJ, Bahrani-Mougeot FK. Bacteremia associated with toothbrushing and dental extraction. Circulation. 2008;117(24):3118-25. doi: 10.1161/ CIRCULATIONAHA.107.758524.

29. Slavkin HC, Baum BJ. Relationship of dental and oral pathology to systemic illness. JAMA. 2000;284(10):1215-7.

30. Parahitiyawa NB, Jin LJ, Leung WK, Yam WC, Samaranayake LP. Microbiology of odontogenic bacteremia: beyond endocarditis. Clin Microbiol Rev. 2009; 22(1):46-64. doi: 10.1128/CMR.00028-08.

31. Baltimore RS, Gewitz M, Baddour LM, Beerman LB, Jackson MA, Lockhart PB, et al. Infective endocarditis in childhood: 2015 update a scientific statement from the American heart association. Circulation. 2015;132(15):1487-515. doi: 10.1161/ CIR.0000000000000298.

32. Wong DT. Salivary Diagnostics. Singapore: WileyBlackwell; 2008.

33. Busuttil Naudi A, Mooney G, El-Bahannasawy E, Vincent C, Wadhwa E, Robinson D, et al. The dental health and preventative habits of cardiac patients attending the Royal Hospital for Sick Children Glasgow. Eur Arch Paediatr Dent. 2006;7(1):23-30. 